\title{
Amyloid polyneuropathy in two German-American families: a new transthyretin variant (Val 107)
}

\author{
T Uemichi, M A Gertz, M D Benson
}

\begin{abstract}
We report studies on two GermanAmerican persons with systemic amyloidosis. Affected subjects presented with carpal tunnel syndrome in the sixth decade of life followed by peripheral neuropathy. DNA analysis of the transthyretin gene showed a new point mutation which is responsible for substitution of valine for isoleucine at position 107 of the transthyretin molecule.
\end{abstract}

( $(\mathcal{F}$ Med Genet 1994;31:416-417)

Familial amyloid polyneuropathy (FAP) is a late onset autosomal dominant disorder characterised by systemic amyloid deposition. ${ }^{1}$ Although more than 40 transthyretin (TTR) gene mutations responsible for the disease have been identified, in many cases the genetic disorder remains unknown.

In this study we report a new mutation in exon 4 of the TTR gene which is associated with amyloid polyneuropathy and also a restriction enzyme analysis to detect the mutation.

\section{Case reports}

CASE 1

A 74 year old man developed tingling and numbness in both hands at the age of 56 and received surgical carpal tunnel releases. He had similar symptoms in his distal lower extremities at the age of 65 . Amyloid deposition was proven by quadriceps muscle biopsy. $\mathrm{He}$ also suffered from a thyroid disorder but further information was not available. Revised version accepted for publication 4 November 1993
CASE 2

A 61 year old man noticed burning sensation in his fingers and was diagnosed to have carpal tunnel syndrome at the age of 56 . He subsequently developed polyneuropathy in his lower limbs. He had weight loss, severe dysgeusia with a metallic taste in his mouth, severe constipation, and sexual impotence. Biopsied specimens of sural nerve, rectum, and flexor retinaculum showed amyloid deposition. His father died at the age of 60 of a very similar illness and the necropsy showed amyloidosis. Four of his father's sibs had similar symptoms, but no additional details were available.

Both patients are American of German descent.

\section{Methods}

DNA of FAP patients was screened for polymorphisms in the TTR gene by single strand conformation polymorphism (SSCP) analysis and exons 2, 3, and 4 of the TTR gene were examined by the direct DNA sequencing method as previously described. ${ }^{2}$ As the $A$ to $G$ transition at the first base of codon 107 does not create or destroy a restriction enzyme recognition site, PCR induced mutation restriction analysis (PCR-IMRA) was developed to detect the mutant gene. A new primer with a mutation arranged to give a recognition site for MaeIII in the mutant gene PCR amplification product (5'GGGCTCAGCAGGGCGGTAA$3^{\prime}$ ) was used with E4LP1 primer (5'TCTGCTGCAGATGGATCTGTCTGTCTTCTC$\left.3^{\prime}\right)$ for PCR. Thirty five cycles of amplification consisted of denaturation at $94^{\circ} \mathrm{C}$ for 30 seconds, annealing at $55^{\circ} \mathrm{C}$ for 30 seconds, and extension at $72^{\circ} \mathrm{C}$ for one minute. PCR products were digested with MaeIII (Boehringer Mannheim Biochemicals, Indianapolis, IN) and electrophoresed through agarose gel.

\section{Results and conclusions}

SSCP analysis showed abnormally migrating bands for exon 4 PCR product of affected subjects (fig 1) and showed a normal pattern for exons 2 and 3. Direct DNA sequencing showed both adenine and guanine at position 6730 of the TTR gene. ${ }^{3}$ Thus they were heterozygous with both a normal ATT (isoleucine) and a variant GTT (valine) codon corresponding to amino acid position 107 of mature TTR. PCR-IMRA showed that affected persons had the MaeIII recognition site associated with the Val 107 mutation and 
Normal gene $-A T$ TÁC-- 98 bp

Val 107 gene
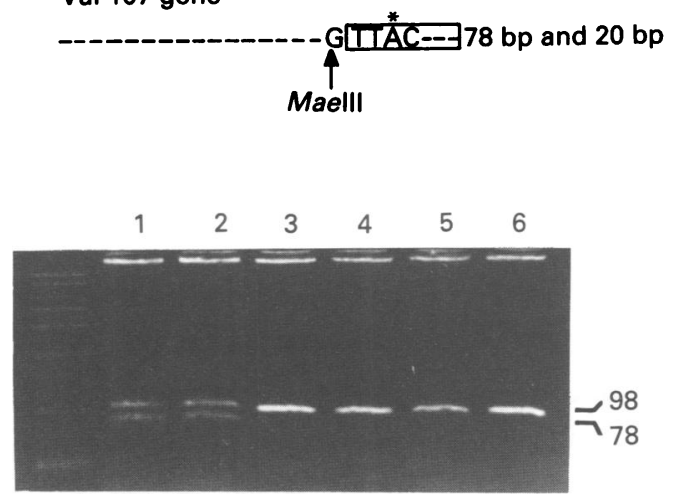

Figure 2 Detection of transthyretin Val 107 gene by $P C R$ induced mutation restriction analysis.

Asterisks = PCR induced mutation. Lane 1, case 1; lane 2, case 2; lanes $3,4,5$, and 6, control subjects. therefore had a digestion band of $78 \mathrm{bp}$, while normal controls showed a band of $98 \mathrm{bp}$ (fig 2).

Since carpal tunnel syndrome is a symptom commonly observed in non-amyloidosis patients, the diagnosis of FAP is often missed in patients presenting with carpal tunnel syndrome. When patients with carpal tunnel syndrome have a family history or develop lower limb neuropathy or autonomic neuropathy or both, DNA testing for TTR mutations should be considered.

This work was supported by Veterans Affairs Medical Research (MRIS 583-0888), and grants from RR-00750 (GCRC), United States Public Health Service, NIDDK-34881, NIDDK-42111, AG 10608, National Institute of Arthritis Metabolism and Digestive Diseases (AM20582), The Arthritis Foundation, and The Marion E Jacobson Fund

1 Benson MD. Inherited amyloidosis. f Med Genet 1991; 28:73-8.

2 Uemichi T, Murrell JR, Zeldenrust S, Benson MD. A new mutant transthyretin (Arg 10) associated with familial amyloid polyneuropathy. $\mathcal{F}$ Med Genet 1992;29:888-91.

3 Tsuzuki T, Mita S, Maeda S, Araki S, Shimada K. Structure of human prealbumin gene. $\mathcal{F}$ Biol Chem 1985;260:12224 